\title{
AGROTÓXICOS: IMPACTOS AO MEIO AMBIENTE E À SAÚDE HUMANA
}

\author{
Fabiola Azevedo Mello, Marcela de Andrade Bernal Fagiani, Renata Calciolari Rossi e Silva, Gisele \\ Alborghetti Nai
}

Universidade do Oeste Paulista (UNOESTE), Doutorado em Fisiopatologia e Saúde Animal, Presidente Prudente, SP. Email: fabiola-azevedo@hotmail.com

\section{RESUMO}

Com a expansão demográfica, aumentou-se a demanda na produção de alimentos e utilização intensa de agrotóxicos, visando o alto índice de produção. A exposição do homem aos agrotóxicos representa um grave problema de saúde pública, que parece não haver solução. O objetivo desta revisão foi abordar os impactos causados ao meio ambiente e à saúde humana, em decorrência do uso de agrotóxicos. Realizouse uma revisão bibliográfica narrativa, com levantamento de artigos científicos sobre o uso de agrotóxicos no Brasil, entre 1997 a 2018, utilizando descritores como agrotóxicos, saúde humana, Brasil e contaminação. Foram encontradas várias patologias e alterações no organismo humano em decorrência da exposição aos agrotóxicos. Os trabalhadores rurais devem utilizar proteção básica diante da exposição aos agrotóxicos e a técnica de pulverização aérea deve ser realizada e programada corretamente, para que o fenômeno da deriva seja minimizado, diminuindo a contaminação humana e ambiental.

Palavras-chave: Agrotóxicos, saúde pública, meio ambiente, poluição ambiental, contaminação.

\section{PESTICIDES: IMPACTS TO THE ENVIRONMENT AND HUMAN HEALTH}

\begin{abstract}
With the demographic expansion, the demand in the food production and intense use of pesticides was increased, aiming the high index of production. The exposure of humans to pesticides is a serious public health problem, and there seems insoluble. The objective of this review was to address the impacts caused to the environment and to human health, due to the use of pesticides. A bibliographic review was carried out, with a survey of scientific articles on the use of pesticides in Brazil, from 1997 to 2018, using descriptors such as pesticides, human health, Brazil and contamination. Several pathologies and changes in the human organism were found due to the exposure to pesticides. Rural workers must use basic protection against exposure to pesticides, and the aerial spraying technique must be carried out and programmed correctly, so that the phenomenon of drift is minimized, reducing human and environmental contamination.
\end{abstract}

Keywords: Agrochemicals, Public Health, Environment, environmental pollution, contamination.

\section{INTRODUÇÃO}

Nos últimos anos, o elevado crescimento demográfico forçou o aumento da produção de alimentos e a utilização intensa de defensivos agrícolas, visando o alto índice de produção. A descoberta do potencial de algumas substâncias em relação ao controle de pragas, plantas daninhas e fungos indesejáveis na agricultura, possibilitaram o aumento das áreas para o cultivo, além da produção de alimentos ${ }^{1}$.

A perfilhação, no Brasil, dos termos agrotóxicos, pesticidas, defensivos agrícolas e agroquímicos é apontada por diversas controversas. A palavra agrotóxico foi definida 
pela legislação brasileira através da Lei 7.802/89 e dos Decretos 98.816/90 e 4.074/2002. Neste trabalho, o termo agrotóxico foi utilizado com o intuito de abranger diferentes esferas de seu uso (herbicidas, inseticidas, fungicidas, etc) ${ }^{2}$.

Os agrotóxicos são utilizados com 0 objetivo de proteger as diferentes culturas de doenças, pragas e plantas daninhas, mas por outro lado, trazem riscos à saúde humana. A exposição do homem aos agrotóxicos apresenta grave problema de saúde pública e que acomete, principalmente, os países que estão em desenvolvimento. Desde o ano de 2009, o Brasil é considerado o maior consumidor de agrotóxicos e também o principal produtor agrícola mundial ${ }^{3}$. Seu crescimento, em 2005, foi de 7 quilos por hectare, equivalente a um aumento de $43,2 \%{ }^{4}$.

$\mathrm{O}$ estado do Mato Grosso é considerado o maior consumidor de agrotóxicos do Brasil (18,9\%), seguido de São Paulo (14,5\%), Paraná $(14,3 \%)$ e Rio Grande do Sul $(10,8 \%)^{4}$.

O objetivo da presente revisão bibliográfica é abordar os impactos provocados ao meio ambiente e à saúde humana, em decorrência do uso de agrotóxicos.

\section{MÉTODOS}

Realizou-se uma revisão bibliográfica narrativa da literatura, com levantamento de artigos científicos sobre agrotóxicos, entre os anos de 1997 e 2018, sem restrição de idioma. Utilizaram-se as seguintes bases de dados: Google acadêmico, BVS-Vet (Pubmed Central) e Lilacs (Literatura Latino-americana e do Caribe em Ciências da Saúde). Os descritores utilizados foram: agrotóxicos, Brasil, contaminação, saúde humana. Foram encontrados, aproximadamente, 15.700 artigos nas bases pesquisas e destes, foram utilizados 44 artigos.

\section{REVISÃO DE LITERATURA \\ Agrotóxicos utilizados no Brasil}

Os últimos 10 anos foram marcados pelo aumento significativo do consumo de agrotóxicos em todo o mundo 5 . A cultura da soja ocupou no Brasil, em 2012, a maior área plantada com cerca de 24 milhões de hectares e em 20 anos, cresceu cerca de $100 \%$. Por outro lado, a cana-de-açúcar duplicou sua área plantada em aproximadamente 10 anos $^{4}$. Com isso, o aumento do uso de agrotóxicos está intimidamente relacionado à expansão destes cultivos.

O aumento da venda de agrotóxicos no Brasil deu-se entre os anos de 2002 e 2003. Entre
2005 e 2006 foi observada uma queda em suas vendas, seguida por um aumento significativo a partir de 2006, apresentando uma leve diminuição em $2009^{4}$.

Um dos principais fatores que dificultam a produção de alimentos no país e também em todo o mundo é a prevenção e o controle de pragas, patógenos e plantas daninhas, que são considerados os grandes responsáveis por perdas significativas no campo ${ }^{6}$. Essa problemática resulta em diversos danos à lavoura, provocando o aumento dos preços, a diminuição da qualidade e o aumento da importação de alimentos ${ }^{7}$.

Os agrotóxicos podem ser classificados de diferentes maneiras como, por exemplo, de acordo com a ação do ingrediente ativo no alvo do organismo desejado: bactericidas, acaricidas, fungicidas, herbicidas, inseticidas, algicidas, rodenticidas, entre outros ${ }^{8}$. De acordo com a Agência Nacional de Vigilância Sanitária (ANVISA), os agrotóxicos também podem ser classificados de acordo com os efeitos agudos que o composto é capaz de produzir após uma única exposição ${ }^{8}$. Essa classificação deve estar presente no rótulo dos produtos, em decorrência de uma determinação legal $\left.\right|^{9}$ :

- Classe toxicológica I: Extremamente tóxico e a faixa colorida presente no rótulo do produto é de cor vermelha;

- Classe toxicológica II: Altamente tóxico e a faixa colorida presente no rótulo do produto é de cor amarela;

- Classe toxicológica III: Moderadamente tóxico e a faixa colorida presente no rótulo do produto é de cor azul;

- Classe toxicológica IV: Pouco tóxico e a faixa colorida presente no rótulo do produto é de cor verde.

Estima-se que em 2013, comercializaramse no Brasil 495.764,55 toneladas de ingredientes ativos $^{10}$. Ao analisar os cinco ingredientes ativos mais vendidos no país naquele ano, destacou-se o glifosato, totalizando 185.956,13toneladas. O glifosato é um herbicida classificado como sendo de baixa toxicidade (Classe IV), mas há estudos que evidenciam deformações em embriões de vertebrados, que foram expostos a esse agrotóxico, em baixas concentrações ${ }^{11}$.

Em relação aos registros dos agrotóxicos, há normas para que eles sejam autorizados e comercializados no país. Para que isso ocorra, há órgãos responsáveis pela aprovação (autorização) desses ingredientes no país como, por exemplo, o 
Ministério da Saúde (MS), Ministério do Meio Ambiente (MMA) e ANVISA ${ }^{5}$.

Há alguns agrotóxicos que são proibidos em alguns países e tem seu uso liberado no Brasil (Tabela 1). As empresas fabricantes desses ingredientes ativos instalam suas unidades de produção em países onde os mesmo têm seu uso autorizado ${ }^{5}$.

Tabela 1. Agrotóxicos com uso autorizado no Brasil e proibidos em outros países.

\begin{tabular}{|c|c|}
\hline Agrotóxicos & Culturas autorizadas no Brasil \\
\hline Aldicard & Algodão, amendoim, banana, batata, café, cana, feijão e tomates \\
\hline Aldrin & $\begin{array}{l}\text { Algodão, arroz, bananas, essências florestais, uso localizado contra cupins e } \\
\text { formigas }\end{array}$ \\
\hline Benomyl & Quase todas as culturas \\
\hline Butacloro & Arroz \\
\hline Captam & Frutos, hortaliças, cereais e leguminosas \\
\hline Diflubenzuron & Couve, couve-flor, soja e algodão \\
\hline Carbaryl & Grande número de culturas, de uso externo em animais e domissanitários \\
\hline Carbofuran & Arroz, repolho, milho, cana e café \\
\hline Clorobenzilato & $\begin{array}{l}\text { Citros, melancia, melão, mamão, morango, hortaliças não folhosas, algodão, } \\
\text { amendoim, girassol, chá, feijão, batata, café e alfafa }\end{array}$ \\
\hline Diclorvos & $\begin{array}{l}\text { Cebola, citros, maçã, melancia, morango, hortaliças em geral, grão-de-bico, } \\
\text { batata, algodão, amendoim, soja, cereais, cacau, café e outros; emprego } \\
\text { domissanitários, inclusive venda livre em aerosol }\end{array}$ \\
\hline Dimetoato & Maçã, pêssego, morango, citros, cucurbitáceos, hortaliças, batata,alho, \\
\hline Dodecacloro & Controle ao combate à saúva \\
\hline Endosulfan. & $\begin{array}{l}\text { Citros, bulbos, cereais, hortaliças, leguminosas, batata, algodão, soja, café e } \\
\text { alfafa }\end{array}$ \\
\hline Endrin & Algodão, milho e soja \\
\hline Folpet & Bulbos, citros, aipo, alface e trigo \\
\hline Lindano & $\begin{array}{l}\text { Algodão, bulbos, café, cana, cítros (exceto morango), hortaliças, } \\
\text { leguminosas, mandioca, cereais e aplicação tópica em animais. Uso } \\
\text { domissanitário nãoautorizado }\end{array}$ \\
\hline Heptacloro & $\begin{array}{l}\text { Arroz, milho, cana, banana, essências florais e aplicação localizada no } \\
\text { controle de cupins eformigas }\end{array}$ \\
\hline Mancozeb (Maneb/ & Quase todas as culturas de bulbo \\
\hline Naled. (DIBROM) & Cebola, batata, arroz, couve, couve-flor, brócoli, repolho, \\
\hline Parathion Etílico & $\begin{array}{l}\text { Bulbos, cereais, frutas, hortaliças, legumes, batata, algodão, amendoim, } \\
\text { cana, café, alfafa e pastagens }\end{array}$ \\
\hline Paraquat & Muitas culturas \\
\hline PCNB (Quintozene) & $\begin{array}{l}\text { Bulbos, cereais, hortaliças, leguminosas, batata, algodão, amendoim, cana, } \\
\text { café, alfafa, sorgo emandioca }\end{array}$ \\
\hline Pirimicarb & Trigo,pepino,hortaliças,feijão,feijão- vagem ebatata \\
\hline
\end{tabular}

Fonte: ANVISA, $2018^{12}$.

Dos 50 agrotóxicos mais utilizados no Brasil, 22 deles são proibidos na União Européia, o que faz com que o país seja considerado o maior consumidor de agrotóxicos já banidos em outros países. De acordo com a Lei 7.802 de 1989 , devem ser proibidos os agrotóxicos que se relacionam com a possibilidade de causar carcinogênese, teratogênese, mutagênese e 
alterações hormonais ou no aparelho reprodutor ${ }^{5}$. Mas o que se vê atualmente são enormes desafios observados no campo da ciência e do governo, já que são publicados, frequentemente, trabalhos que demonstram diferentes alterações em decorrência da exposição aos agrotóxicos e mesmo assim, eles ainda continuam sendo comercializados no país, como é o caso do Endosulfan 5 .

\section{Impactos ao meio ambiente}

\section{Contaminação do solo e dos recursos hídricos}

A água e o solo são recursos naturais e essenciais para que haja a sobrevivência de todo o Planeta. A produção de alimentos depende desses recursos, porém a utilização de diversas e modernas técnicas nos sistemas de produção provocou a inserção de uma imensa variedade de substâncias sintéticas no meio ambiente ${ }^{14}$.

O solo consegue absorver quantidades significativas de contaminantes sem apresentar grandes alterações. No entanto, com o passar dos anos, as transformações sofridas por ele tornaram-se irreversíveis, na maioria dos casos, e os danos causados ao ambiente mostram-se de difícil recuperação ${ }^{15}$.

No momento em que uma partícula de agrotóxicos é aplicada no meio ambiente, ela atinge o solo, independentemente da maneira como foi aplicada- pulverização aérea ou diretamente no solo ${ }^{14}$. Aproximadamente $50 \%$ de todo 0 produto sofre diversos processos químicos, físicos e biológicos, que determinam seu comportamento, além de serem dispersos para outros compartimentos presentes no ecossistema, como a água e a atmosfera ${ }^{16}$.

Essas substâncias podem ser depositadas no solo por meio do uso de água contaminada na aplicação dos defensivos agrícolas, manejo direto do agrotóxico no controle de plantas daninhas ou por contaminação quando em contato com embalagens dos defensivos que não foram devidamente descartados durante a tríplice lavagem ${ }^{14}$.

Existem diferentes formas nas quais esses compostos podem ser encontrados no meio aquático: escoamento superficial, lixiviação e através de sua evaporação para a atmosfera, contaminando os recursos hídricos por meio da precipitação ${ }^{17}$.

O escoamento superficial propicia a contaminação das águas superficiais, devido ao transporte do agrotóxico absorvido às partículas do solo ou em solução. A lixiviação resulta da contaminação das águas subterrâneas através do transporte dos defensivos junto com a água que alimenta os rios ${ }^{16}$. Além disso, a contaminação pode prejudicar a saúde humana de maneira direta, ainda mais quando os recursos são utilizados como fonte de água potável para a sociedade $^{18}$.

Alguns agrotóxicos, quando presentes no meio ambiente ou ao atingirem o ambiente aquático, oferecem riscos às espécies de animais ali presentes, devido a sua toxicidade e capacidade de bioacumular-se ao longo de toda a cadeia alimentar ${ }^{19}$.

\section{Pulverização aérea}

O Brasil destaca-se em relação à produção de algodão, alimentos, madeira, celulose e biocombustíveis ${ }^{20}$. Seu modelo vincula-se fortemente ao uso de agrotóxicos e por isso, é considerado o maior consumidor do mundo ${ }^{13}$. Ainda de acordo com os autores, na safra de 2012, a agricultura brasileira pulverizou aproximadamente 1,05 bilhões de litros de agrotóxicos. Diante deste cenário, os impactos causados ao meio ambiente e a saúde humana tornaram-se uma verdadeira ameaça à qualidade de vida de todas as gerações ${ }^{13}$.

A pulverização de agrotóxicos sobre uma área específica, condicionada a critérios meteorológicos, produz desvios na trajetória das gotas em relação ao alvo desejado, ocasionando na perda do produto, processo conhecido como deriva ${ }^{21}$. Sendo assim, o objetivo da técnica de pulverização aérea é administrar a quantidade correta de agrotóxicos no alvo desejado, com eficácia e de maneira econômica, sem que haja contaminação ambiental ${ }^{22}$.

Se a pulverização aérea não for feita de acordo com as condições meteorológicas adequadas, é presumível que parte dela sofrerá deriva. Além disso, é de extrema importância que se conheça qual a maneira de aplicação do produto, com o intuito de minimizar os desvios de trajetóriao que pode acarretar em impactos à saúde humana e ao meio ambiente ${ }^{21}$.

A maioria dos impactos negativos em decorrência da prática de pulverização aérea é observada com maior frequência em áreas ao redor das plantações, em especial nas pequenas propriedades rurais ${ }^{23}$.

O município de Lucas do Rio Verde, localizado no estado do Mato Grosso, apresenta fortes indícios dos efeitos da pulverização aérea relacionado à contaminação dos alimentos, da 
água e do ar. Já foram realizadas pesquisas que tentaram identificar resíduos de agrotóxicos em diversos elementos, dando destaque ao leite materno de mães residentes no município. Em um destes estudos, foram coletadas 62 amostras de leite proveniente das mães que estavam amamentando e detectou-se, em todas as amostras, a presença de agrotóxicos ${ }^{24}$.

Em um estudo realizado, os entrevistados relataram que os principais sintomas sentidos por eles durante a pulverização aérea de agrotóxicos foram: cefaléia, olhos ardendo e boca seca. Os sintomas duravam de 3 a 5 dias após a pulverização ${ }^{25}$.

Outro estudo conclui que não há condições de se realizar a técnica de pulverização aérea de forma segura na região do Pontal do Paranapanema, visto que os parâmetros meteorológicos (velocidade dos ventos, umidade relativa do ar) são impróprios e que mesmo assim, a prática é realizada na região provocando diversos impactos ao meio ambiente e à saúde humana ${ }^{23}$.

\section{Impactos a saúde humana}

\section{A exposição humana aos agrotóxicos}

O Brasil ainda é conhecido por apresentar uma economia baseada na agricultura, cujo potencial é voltado para o desenvolvimento da indústria de adubos e agrotóxicos para as lavouras. Com o crescimento da demanda nesse setor, os produtos aumentaram significativamente sua produção e reduziram as perdas na safra. Isso se deve ao uso desenfreado e indiscriminado de agrotóxicos, colocando em risco a saúde dos indivíduos que ficam expostos a essas substâncias. Há indícios de que os agrotóxicos têm sido utilizados no Brasil, desde as décadas de 60 e 70, a fim de controlar vetores e pragas na área da saúde pública ${ }^{26}$.

A motivação para as pesquisas relacionadas com a utilização inadequada e aos efeitos nocivos causados pelos agrotóxicos teve início a partir de 1962, pela obra "Primavera Silenciosa" de Rachel Carson, a qual abordou a presença destes efeitos nocivos, sendo que os resíduos dos agrotóxicos se acumularam no tecido adiposo dos animais, consumidos os sobre a forma de alimentos pelos seres humanos, bem como seu acúmulo nos adipócitos do homem, aumentando os riscos para o desenvolvimento de neoplasias e alterações genéticas ${ }^{26}$.

A exposição aos agrotóxicos ocorre por diferentes vias. A via inalatória (por meio da respiração) e dérmica (pele), são as vias que propiciam o transporte dos agrotóxicos para a corrente sanguínea, além de serem as vias de exposição mais comuns em indivíduos que trabalham com essas substâncias ${ }^{27}$. Também fazem parte desse grupo, pessoas que se localizam próximas às áreas onde ocorre a pulverização das substâncias e/ou também contato com água e/ou alimentos contaminados. Outra forma de contaminação que deve ser destacada é a oral, relacionada à ingestão de alimentos e/ou água também contaminados. 0 embrião e o feto, ainda em formação, através da placenta, podem entrar em contato com o agrotóxico caso a mãe tenha sido exposta antes ou durante a gestação ${ }^{28}$.

A exposição humana aos agrotóxicos pode ser classificada de acordo com a frequência de exposição em: aguda (ocorre em um curto período de tempo, geralmente inferior a 24 horas, e se caracteriza por uma única exposição e em grandes quantidades de agrotóxicos), subaguda (semelhante à exposição aguda, mas o tempo de exposição é maior, de alguns dias a 1 mês), subcrônica (exposições repetidas em um intervalo de tempo de 1 a 3 meses e em baixas doses de agrotóxicos) e crônica (exposições repetidas ou contínuas a baixas doses de agrotóxicos acima de 3 meses). Em exposições agudas, os efeitos manifestam-se, geralmente, nas primeiras 24 horas após a exposição. As tentativas de suicídio e pulverização são exemplos desse tipo de exposição ${ }^{29}$.

Dependendo da via de absorção que o agrotóxico percorre, ele pode ser metabolizado de maneiras e/ou velocidades diferentes, formando produtos diferentes que podem ser mais danosos ou não, dependendo da concentração, idade do indivíduo e presença de outros contaminantes ${ }^{30}$.

Os níveis de agrotóxicos utilizados têm sido mais encontrados nas regiões agrícolas do Brasil, provavelmente, isto se relaciona com a vasta utilização, o não cumprimento das normas de utilização, o comércio livre desses produtos e a cobrança das indústrias alimentícias sobre a produção dos alimentos. Além disso, podem ser considerados fatores de risco para a contaminação por agrotóxicos, o ato de reentrar na lavoura após a aplicação, a utilização do equipamento de proteção por período superior a 10 dias mensais e a manipulação dos agrotóxicos em mais de uma propriedade ${ }^{31}$. 
Toxicidade aguda e crônica associada à exposição aos agrotóxicos

Quando empregados nas plantações, os agrotóxicos apresentam a possibilidade de se dissiparem e desviam-se de sua finalidade primária, que é o combate a algumas espécies em específico, com isso podem apresentar efeitos inesperados em outros constituintes do meio ambiente como, por exemplo, os seres humanos ${ }^{32}$.

São descritos na literatura diversas patologias e/ou alterações no organismo humano em decorrência da exposição aos agrotóxicos ${ }^{33,34}$. Um estudo mostrou maior incidência de leucemia linfóide crônica em veteranos neozelandeses que participaram da Guerra do Vietnã e que foram expostos ao "Agente Laranja", quando comparados à população em geral ${ }^{34}$.

Em intoxicações agudas, os sintomas e os sinais são nítidos e aparecem rapidamente. $\mathrm{Na}$ maioria desse tipo de intoxicação são observadas dormência na língua, lábios e membros inferiores, cefaléia constante, fraqueza, vertigens, náuseas, vômitos, tremores, convulsões, coma e até a morte. Caso o agrotóxico tenha sido inalado, o indivíduo pode apresentar rouquidão, tosse, edema pulmonar, taquicardia e broncopneumonia ${ }^{34}$.

Fraqueza, cefaléia, mal-estar, dor de estômago e sonolência são os principais sinais e sintomas de intoxicações subagudas e surgem de maneira mais lenta? ${ }^{7}$.

Os sinais e sintomas das intoxicações crônicas e subcrônicas surgem tardiamente e se caracterizam por alterações no Sistema Nervoso, como cefaléia, vertigens, excitabilidade e contrações musculares involuntárias ${ }^{5}$; hormonais e metabólicas, como atrasos no desenvolvimento em crianças e as relacionadas à reprodução, bem como o aborto; no sistema imunológico, pode causar imunossupressão; no sistema respiratório, as alterações podem iniciar-se com irritações no nariz e garganta e evoluir para broncoconstrição, dispnéia e enfisema, principalmente em indivíduos que já possuem doenças respiratórias, como por exemplo, asma ${ }^{35}$.

Além disso, o contato com os agrotóxicos pode ter efeitos nas células sanguíneas, pois o monóxido de carbono se liga à molécula de hemoglobina, impedindo sua capacidade de transportar oxigênio, e afetam consequentemente, órgãos nobres como o cérebro (o principal efeito relatado é a isquemia), coração e corrente sanguínea ${ }^{35}$. Pode haver também influência sobre a coagulação sanguínea, e com isso, causar angina, infarto agudo do miocárdio (IAM) e taquicardia ${ }^{36}$, bem como inibir a hematopoese, causando anemia ${ }^{37}$.

Há relatos de que indivíduos apresentaram câncer de fígado, intestino ${ }^{35}$, pâncreas, linfoma não-Hodgkin e mama por conta da exposição crônica aos agrotóxicos ${ }^{38}$.

Em um estudo realizado com agricultores expostos aos organofosforados mostrou que estes apresentavam sintomas de depressão ${ }^{39} . \mathrm{Em}$ outro com trabalhadores rurais expostos aagrotóxicos, foi observado o desenvolvimento de leucemia mielóide aguda ${ }^{40}$.

\section{Monitoramento da exposição humana aos agrotóxicos}

Dentre as classes de agrotóxicos existentes no mercado, os herbicidas são os que mais predominam seguidos dos pesticidas, inseticidas e fungicidas ${ }^{41}$. A gravidade da exposição a esses produtos pode variar entre os indivíduos, categoria química, dose, duração da exposição e o tipo de exposição. Apesar de sua aplicação ser direcionada para as plantas, podem ocorrer fenômenos que favoreçam a deriva destes tóxicos, principalmente quando há a mistura destes produtos, facilitando a ocorrência de toxicidade nos seres humanos ${ }^{41}$.

Existem alguns órgãos que fiscalizam as quantidades de agrotóxicos no ambiente (solo, alimentos, ar, água) como, por exemplo, a Entidade Européia de Segurança Alimentar (European Food Safety Authority - EFSA). A EFSA estima a exposição alimentar dos consumidores aos resíduos de agrotóxicos, e a exposição esperada é comparada com os níveis aceitáveis de exposição a fim de avaliar o risco para os consumidores ${ }^{42}$.

Segundo a $\mathrm{EFSA}^{42}$, analisando os dados referentes às amostras provenientes da União Européia, 97,1\% destas, encontravam-se dentro dos limites permitidos, $43,4 \%$ continham resíduos dentro do permitido e $1,5 \%$ excederam os limites permitidos para as concentrações de agrotóxicos nos alimentos.

A partir da identificação do risco da contaminação, algumas medidas são tomadas, as infrações são compartilhadas com os gestores de risco, que incluem os diretores das empresas do setor alimentar, e são realizadas ações a fim de melhorar a conscientização sobre as áreas mais afetadas, e assim, há a elaboração de atividades de controle de contaminação ${ }^{42}$. 
Já no Brasil, vale ressaltar que o mesmo ocupa desde 2008, o ranking do país onde mais se consome agrotóxicos no mundo ${ }^{5}$.

Segundo dados do Programa de Análise de Resíduos de Agrotóxicos em Alimentos (PARA) PARA $(2010)^{43}$, foram analisadas amostras de alimentos, e constatou-se que $63 \%$ destes, apresentaram contaminação por agrotóxicos, $28 \%$ continham substâncias não autorizadas para aquele determinado cultivo, ou as substâncias encontravam-se em maior proporção do que o recomendado.

Segundo a ANVISA ${ }^{44}$, para autorizar a utilização de um ingrediente para a formulação de agrotóxicos, a mesma realiza o cálculo da ingestão diária máxima teórica, que consiste na soma dos produtos do consumo médio por pessoa, por dia, de cada alimento e seu limite máximo de resíduo por peso (Figura 1):

$I D M T=\frac{\sum(\text { LMR } \times \text { Consumo do alimento })}{\text { Peso corpóreo }}$

Figura 1. Fórmula para calcular a ingestão diária máxima teórica para agrotóxicos.

Fonte: ANVISA $(2014)^{44}$

Porém, apesar de haver este cuidado, segundo a Associação Brasileira De Saúde Coletiva $^{5}$, muitos destes produtos são utilizados antes mesmo de ocorrer à permissão para seu uso, acarretando em diversos problemas para a saúde coletiva.

\section{CONSIDERAÇÕES FINAIS}

Olhando o quadro atual do consumo de agrotóxicos no país, algumas perguntas ainda encontram-se sem resposta: Será que não seria mais rentável monitorar a exposição humana aos agrotóxicos? Será que não existe alternativa que substitua o uso dos mesmos e que provoquem menos impactos ao meio ambiente e à saúde humana?

É sabido que tanto a contaminação ambiental quanto a humana é complexa e que é necessário um maior entendimento sobre os impactos da exposição aos agrotóxicos, principalmente por parte do homem do campo, em decorrência de sua maior exposição aos riscos. Outro aspecto bastante importante e que merece destaque são as dificuldades encontradas na organização dos dados de casos de intoxicação no Brasil e também os desafios encontrados na aplicação do monitoramento das intoxicações.

O uso racional e controlado de agrotóxicos é o que poderá minimizar o impacto ambiental e à saúde humana, porém mantendo a produção da lavoura de forma mais sustentável.

\section{DECLARAÇÃO DE CONFLITO DE INTERESSE}

Os autores declaram não haver qualquer potencial conflito de interesse que possa interferir na imparcialidade deste trabalho científico.

\section{REFERÊNCIAS}

1. Monqueiro PA, Amaral LR, Binha DP, Silva $A C$, Silva PV. Potencial de lixiviação de herbicidas no solo submetidos a diferentes simulações de precipitação. Planta Daninha. 2008; 26(2): 403409. DOI: http://dx.doi.org/10.1590/S0100$\underline{83582008000200017}$

2. Faria NMX, Fassa AG, Facchini LA. Intoxicação por agrotóxicos no Brasil: os sistemas oficiais de informação e desafios para realização de estudos epidemiológicos. Ciênc. Saúde Coletiva. 2007; 12(1): 25-38. https://doi.org/10.1590/S1413$\underline{81232007000100008}$

3. Bombardi L. Intoxicação e morte por agrotóxicos no Brasil: a nova versão do capitalismo oligopolizado. Boletim DATALUTA. Nera - Núcleo de Estudos, Pesquisar e Projetos de Reforma Agrária - Universidade Estadual Paulista, Presidente Prudente - SP, 2011.

4. Bombardi LM. Agrotóxicos e agronegócio: arcaico e moderno se fundem no campo brasileiro [tese]. São Paulo: Faculdade de Filosofia, Letras e Ciências Humanas da Universidade de São Paulo, 2012.

\section{ASSOCIAÇÃO BRASILEIRA DE SAÚDE} COLETIVA. Dossiê ABRASCO: um alerta sobre os impactos dos agrotóxicos na saúde. Organização de Fernando Ferreira Carneiro, Lia Giraldo da Silva Augusto, Raquel Maria Rigotto, Karen Friedrich e André Campos Búrigo. Rio de Janeiro: EPSJV; São Paulo: Expressão Popular, 2015.

6. Godoy RCB, Oliveira MI. Agrotóxicos no Brasil: processo de registro, riscos à saúde e programas de monitoramento. Crus das Almas - 
BA: Embrapa Mandioca e Fruticultura Tropical, 2004.

7. Ramos A, Silva Filho JF. Exposição a pesticidas, atividade laborativa e agravos à saúde. Revista Médica de Minas Gerais. 2004; 14(1): 4145.

8. Oliveira TG, Favareto APA, Antunes PA. Agrotóxicos: levantamento dos mais utilizados no Oeste Paulista e seus efeitos como desreguladores endócrinos. IX Fórum Ambiental da Alta Paulista. 2013; 9(11): 375-390. https://doi.org/10.17271/198008279112013684

9. Brasil. Decreto no 4.074 , de 4 de janeiro de 2002. Regulamenta a Lei no 7.802 , de 11 de julho de 1989, que dispõe sobre a pesquisa, a experimentação, a produção, a embalagem e rotulagem, o transporte, o armazenamento, a comercialização, a propaganda comercial, a utilização, a importação, a exportação, o destino final dos resíduos e embalagens, o registro, a classificação, o controle, a inspeção e a fiscalização de agrotóxicos, seus componentes e afins, e dá outras providências. Diário Oficial da União; 4 jan 2002.

10. Cardoso FDP, Almeida MC, Ribeiro RO, Viana SFR, Marques EE, Souza LB. Expansão recente da fronteira agrícola e o consumo de produtos agroquímicos: indicadores e possíveis impactos na saúde do trabalhador do campo em Porto Nacional - Tocantins. RARA. 2017; 9(3): 37$59 . \quad$ https://doi.org/10.18361/21768366/rara.v9n3p37-59

11. Paganelli A, Gnazzo V, Acosta H, López SL, Carrasco AE. Glyphosate-based herbicides produce teratogenic effects on vertebrates by impairing retinoic acid signaling. Chem. Res. Toxicol. 2010; 23(1): 1586-1595. https://doi.org/10.1021/tx1001749

12. Agência de Vigilância Sanitária. ANVISA. Regularização de Produtos - Agrotóxicos. Disponível em:

http://portal.anvisa.gov.br/registros-eautorizacoes/agrotoxicos/produtos/monografiade-agrotoxicos/autorizadas. Acesso em 05 set 2018.

13. Pignati $\mathrm{W}$, Oliveira NP, Silva AMC. Vigilância aos agrotóxicos: quantificação do uso e previsão de impactosna saúde-trabalho-ambiente para os municípios brasileiros. Ciênc. Saúde coletiva. 2014; 19(12): 4669-4678. https://doi.org/10.1590/1413$\underline{812320141912.12762014}$

14. Steffen GPK, Steffen RB, Antoniolli ZI. Contaminação do solo e da água pelo uso de agrotóxicos. Tecno-Lógica. 2011; 15(1):15-21.

15. Mancuso MAC, Negrisoli E, Perim L. Efeito residual de herbicidas no solo ("carryover"). Rev. Bras. Herb. 2011; 10(2):151-164. https://doi.org/10.7824/rbh.v10i2.106

16. Fraga WG, Costa NR, Almeida FV, Rebelo RM, Moraes KOC, Rezende JA et al. Identificação dos principais ingredientes ativos em agrotóxicos ilegais apreendidos pela polícia federal do Brasil e quantificação do mestulfurom-metílico e tebuconazol. Rev. Virtual Quím. 2016; 8(3): 561575.

17. Cattaneo R. Parâmetros metabólicos e histológicos de jundiás (Rhamdia quelen) expostos à formulação comercial do herbicida 2,4 - Diclorofenoxiacético (2,4-D) [tese]. Santa Maria: Centro de Ciências Naturais - Programa de PósGraduação em Ciências Biológicas: Bioquímica Toxicológica da Universidade Federal de Santa Maria, 2009.

18. Martini LFD, Caldas SS, Bolzan CM, Bundt ADC, Primel EG, Avila LA. Risco de contaminação das águas de superfície e subterrâneas por agrotóxicos recomendados para a cultura do arroz irrigado. Ciência Rural. 2012; 42(10): 1715$1721 . \quad$ https://doi.org/10.1590/S0103$\underline{84782012001000001}$

19. Milhome MAL, Sousa DOB, Lima FAF, Nascimento RF. Avaliação do potencial de contaminação de águas superficiais e subterrâneas por pesticidas aplicados na agricultura do Baixo Jaguaribe, CE. Eng. Sanit. Ambient. 2009; 14(3): 363-372. https://doi.org/10.1590/S1413$\underline{41522009000300010}$

20. Bayer T, Costa IFD, Lenz G, Zemolin C, Marquer LN, Stefanelo MS. Equipamentos de pulverização aérea e taxas de aplicação de fungicida do arroz irrigado. R. Bras. Eng. Agric. Ambiental. 2011; 15(2): 192-198. 
https://doi.org/10.1590/S141543662011000200007

21. Madureira RP, Raetano CG, Cavalieri JD. Interação pontas-adjuvantes na estimaiva do risco potencial de deriva de pulverizações. AGRIAMBI. 2015; 19(2): 180-185. https://doi.org/10.1590/1807-

1929/agriambi.v19n2p180-185

22. Alvarenga $C B$, Teixeira $M M$, Zolnier $S$, Cecon PR, Siqueira DL, Rodrigues DE et al. Efeito do déficit de pressão de vapor d'água no ar na pulverização hidropneumática em alvos artificiais. Biosci. J. 2014; 30(1): 182-193. https://doi.org/10.18227/1982-

8470ragro.v8i1.959

23. Boin MN, Jardim FHC, Tavares LFJ. Análise da dinâmica do tempo meteorológico e das possibilidades de aplicação de defensivos agrícolas aéreos no pontal do paranapanema. In: Boin MN, Martins PCS. Planejamento e análises ambientais. Tupã: ANAP, 2017. p. 161-183.

24. Melo GGS, Rodrigues TBS, Souza MMO. O uso de agrotóxicos não é uma escolha do produtor, mas sim uma imposição do agronegócio. Anais do VIII Encontro Dia do Geógrafo - Goiás. 2013; 1(1): 103-107.

25. Regala RMS. Conquistar a terra não é suficiente: o uso de agrotóxicos pela empresa santana e a luta dos assentados do nova vida I pela vida na terra [Trabalho de Conclusão de Curso]. João Pessoa: Universidade Federal da Paraíba, 2014.

26. Burns CJ, Beard KK, Cartmill JB. Mortality in chemical workers potentially exposed to 2,4dichlorophenoxyacetic acid (2,4-D) 1954-94: an update. Occup. Environ. Med. 2001; 58(1): 24-30. https://doi.org/10.1136/oem.58.1.24

27. Carmo ED. Avaliação da ação sistêmica de extrato liofilizado de Pfaffia glomerata na carcinogênese quimicamente induzida pelo DMBA em pele de camundongos Hairless [Tese]. São José dos Campos: Faculdade de Odontologia de São José dos Campos, 2007.

28. Friedrich K. Avaliação dos efeitos tóxicos sobre o sistema reprodutivo, hormonal e câncer para seres humanos após o uso do herbicida 2,4-
D. Rio de Janeiro: Instituto Nacional de Controle de Qualidade em Saúde da Fundação Oswaldo Cruz, 2014.

29. Amarante Júnior OP, Santos TCR, Brito NM, Ribeiro ML. Revisão das propriedades, usos e legislação do ácido 2,4-Diclorofenoxiacético (2,4D). Cad. Pesq. 2002; 13(1): 60-70.

30. Barbosa LR. Uso de agrotóxico e seus impactos na saúde humana e ao meio ambiente: um estudo com agricultores da microbacia hidrográfica do Ribeirão Arara no município de Paranavaí, PR [tese]. Medianeira: Especialização em Gestão Ambiental em Municípios da Universidade Tecnológica Federal do Paraná, 2014.

31. Charles JM, Cunny HC, Wilson RD, Ivett JL, Murli H, Bus JS, Gollapudi B. In vivo micronucleus assays on 2,4-dichlorophenoxyacetic acid and its derivatives. Mutat. Res. 1999; 444 (1): 227-234. https://doi.org/10.1016/S1383-5718(99)00076-5

32. Alavanja MCR, Ross MK, Bonner MR. Increased cancer burden among pesticide applicators and others due to pesticide exposure. CA Cancer J Clín. 2013; 63: 120-142. https://doi.org/10.3322/caac. 21170

33. McBride D, Cox B, Broughton J, Tong D. The mortality and cancer experience of New Zealand Vietnam war veterans: a cohort study. BMJ Open. 2013; 3(9): 1-6. https://doi.org/10.1136/bmjopen-2013-003379

34. Oliveira CS. Vigilância das intoxicações por agrotóxicos no estado do Mato Grosso do Sul: uma proposta de relacionamento entre banco de dados [dissertação]. Campo Grande: Escola Nacional de Saúde Pública Sérgio Arouca, 2010.

35. Kampa M, Castanas E. Human health effects of air pollution. Environ. Pollut. 2008; 151(1):

362-367.

https://doi.org/10.1016/j.envpol.2007.06.012

36. Vermylen J, Nemmar A, Nemery B, Hoylaerts. Ambient air pollution and acute myocardial infarction. J. Thromb. Haemost. 2005; 3(1): $\quad 1961$. https://doi.org/10.1111/j.1538$\underline{7836.2005 .01471 . x}$ 
37. Huang YT, Ghio AJ. Vascular effects of ambient pollutant particles and metals. Curr. Vasc. Pharmacol. 2006; 4(1): 199-203. https://doi.org/10.2174/157016106777698351

38. Longnecker MP, Rogan WJ, Lucier G. The human health effects of DDT (dichlorodiphenyltrichloroethane) and PCBS (polychlorinated biphenyls) and an overview osorganochlorines in public health. Annu. Rev. Public Health. 1997; 18(1):

211-244.

https://doi.org/10.1146/annurev.publhealth.18.1. $\underline{211}$

39. Stallones L, Beseler C. Pesticide poisoning and depressive symptoms among farm residents. Ann. Epidemiol. 2002; 12(6): 389-394. https://doi.org/10.1016/S1047-2797(01)00298-8

40. Beard J, Sladden T, Morgan G, Berry G, Brooks L, McMichael A. Health impacts of pesticide exposure in a cohort of outdoor workers. Environ. Health Perspect. 2003; 111(5): 724-730.

41. Hernández AF, Parrón T, Tsatsakis AM, Requena M, Alarcón R, López-Guarnido O. Toxic effects of pesticide mixtures at a molecular level: their relevance to human health. Toxicology. 2013; 307(1): 136-145. DOI: http://dx.doi.org/10.1016/j.tox.2012.06.009

42. EFSA.European Food Safety Authority.Chemicals in food2016. Itália, 2016.

43. ANVISA. Programa de análise de resíduos de agrotóxicos em alimentos (PARA) - relatório de atividades de 2010. Brasília, 2011.

44. ANVISA. Programa de análise de resíduos de agrotóxicos em alimentos (PARA) - relatório complementar relativo à segunda etapa das análises de amostras coletadas em 2012. Brasília, 2014. 